Дьяконова Валерия Андреевна

Студент магистратуры, ФГБОУ ВО

«Государственный университет

управления», г. Москва

e-mail: dyakonova.v.a@bk.ru

Ершова Наталья Борисовна

канд. экон. наук, ФГБОУ ВО

«Государственный университет

управления», г. Москва

e-mail: natborer@mail.ru

\section{Dyakonova Valeriya}

Graduate student, State University

of Management, Moscow

e-mail:dyakonova.v.a@bk.ru

Ershova Nataliya

Candidate of Economic Sciences, State University of Management, Moscow

e-mail: dyakonova.v.a@bk.ru

\section{РОЛЬ ЛИЗИНГОВЫХ КОМПАНИЙ В ЭКОНОМИКЕ РОССИЙСКОЙ ФЕДЕРАЦИИ}

\begin{abstract}
Аннотация. Увеличение производства и инвестиций в иелях удовлетворения растущего спроса необходимы для устойчивого развития экономики. Лизинг, как инструмент, способен значительно помочь в осуществлении этих задач. Он является значимым фактором экономического роста, способствующим увеличению объема производства товаров и услуг на основе создания новых производственных мощностей и привлечения инвестиционных ресурсов. В статье представлена сравнительная характеристика лизинга в России и других стран мира, описывается сложившаяся ситуация на российском рынке и ее предполагаемое развитие в будущем, выявлены различия между лизинговыми и арендными отнотениями.
\end{abstract}

Ключевые слова: лизинговые отношения, лизингодатель, лизингополучатель, финансовое обеспечение, аренда.

\section{THE ROLE OF LEASING COMPANIES IN THE ECONOMY OF THE RUSSIAN FEDERATION}

\begin{abstract}
Increased production and investment in order to meet growing demand are necessary for the sustainable development of the economy. Leasing, as a tool, can significantly help in the implementation of these tasks. It is a significant factor in economic growth, contributing to an increase in the production volume of goods and services through the creation of new production capacities and the attraction of investment resources. A comparative characteristic of leasing in Russia and other countries of the world has been introduced in the article, the current situation on the Russian market and its expected development in the future is described, the differences between leasing and rental relationship have been revealed.
\end{abstract}

Keywords: leasing relationship, leaser, leasholder, financial security, rent.

В международной практике определение понятия «лизинг» для компаний, составляющих отчетность по международным стандартам финансовой отчетности (далее - МСФО) (страны Европы), содержится в стандарте IAS 17 (МСФО 17), где лизинг определяется как «соглашение, в соответствии с которым арендодатель передает лизингополучателю в обмен на платеж или серию платежей, право на использования актива на согласованный период времени» [12]. Таким образом, лизинг - термин, который используется для описания передачи права пользования основным активом лизингополучателю от лизингодателя на определенный срок в обмен на арендные платежи.

Отметим, что в МСФО 17 лизинг подразделяют на финансовый и операционный. В первом случае все риски и выгоды, связанные с объектом, передаются лизингополучателю, который признает полученный объект как актив компании. Риски могут включать возможности потерь от простоя или технологического устаревания, риски из-за изменения экономических условий. Выгоды могут включать ожидаемую прибыль в течение срока службы актива, выгоды от повышения стоимости актива или реализации остаточной стоимости. В случае операционного лизинга все риски несет владелец актива.

Предметом лизинга может быть движимое и недвижимое имущество. По окончании срока лизинга арендодателю предоставляется право выкупа актива или возобновления аренды в течение определенного периода времени. Стоит отметить, что покупка актива может быть осуществлена до конца периода аренды, если это согласовано в договоре.

Исследования показывают лизинг как сложный социально-экономический феномен, выполняющий несколько ключевых функций в экономике. К основным функциям относят:

(С Дьяконова В.А., Ершова Н.Б., 2019. Статья доступна по лицензии Creative Commons «Attribution» («Атрибуция») 4.0. всемирная (http://creativecommons.org/licenses/by/4.0/).

The Author(s), 2018. This is an open access article under the CC BY 4.0 license (http://creativecommons.org/licenses/by/4.0/).

(c) (i) 
1) финансовую функцию. Лизингополучатель освобожден от единовременного платежа стоимости необходимого ему имущества;

2) производственную функцию, которяа направлена на решение промышленных проблем путем временного использования и последующего выкупа актива, а не покупки дорогостоящих активов. Это эффективный способ расширения производства и доступа к новейшим технологиям, научно-техническим достижениям;

3) функцию получения налоговых льгот (при финансовом лизинге).

Иногда финансовый лизинг называют формой среднесрочного и долгосрочного финансирования бизнеса, для приобретения основных средств (например, машин и оборудования), которые имеют большое значение для успешного продолжения деятельности, роста компании. Лизинг представляет собой альтернативный способ финансирования деятельности предприятий по сравнению с традиционными способами среднесрочных банковских кредитов. М. И. Лещенко в своей работе «Основы лизинга» представляет лизинг как товарный кредит, который предоставляется лизингодателем в виде переданного в пользование имущества лизингополучателю [5].

По мнению зарубежных специалистов, лизинг как форма финансирования имеет преимущества для лизингодателя, лизингополучателя и для национальной экономики. Лизингополучатель получает финансирование, процедуры быстрые и простые. При этом лизинг не требует дополнительных гарантий, как при ипотечном и иных видах кредитования. Есть возможность выбора гибкого графика платежей, что очень важно, особенно для предприятия, деятельность которого подвержена сезонным колебаниям. Кроме того, бизнес защищен от технологического обесценивания оборудования. Через процедуру лизинга арендатор может получить капитальное оборудование без установления кредитного лимита (при банковском кредитовании) и без единовременного использования собственных средств [15, с. 39].

Однако приобретение активов в лизинг имеет и существенные недостатки. Согласно международному опыту стоимость лизинга обычно немного выше, чем стоимость эквивалентного банковского кредитования. Поэтому выбор между лизингом или использованием банковского кредита должен основываться на анализе каждого случая отдельно, так как информация (стоимость капитала, амортизация и т. д.) различается в каждом конкретном случае. Используемая процентная ставка отличается, как при выборе лизинговых компаний, так и при установлении периода лизинга. Кроме того, изменение процентных ставок зачастую происходят в соответствии с условиями, которые существуют на рынке, и следовательно оказывают влияние на лизинговые платежи.

Таким образом, финансовые причины преобладают в качестве наиболее важных мотиваторов для использования лизинга. Другой часто упоминаемый аргумент в зарубежной литературе в пользу финансового лизинга заключается в том, что он позволяет арендодателю свести к минимуму затраты, с которыми он столкнулся бы в потенциальной ситуации банкротства лизингополучателя. Действительно, в случае невыполнения обязательств по лизинговым платежам финансовые интересы арендодателя в значительной степени защищены. Например, арендодатель имеет право на получение арендованного имущества, в случае нарушения договорных обязательств со стороны лизингополучателя.

Современное развитие лизинговых отношений в Российской Федерации (далее - РФ) началось в 19881989 гг, когда были внедрены арендные формы хозяйствования. К 1989 г. объемы лизинговых платежей составили около 400 млн долл. США, что соответствовало 32 месту на мировом рынке [4]. В 1993 г. на территории России функционировали 7 лизинговых компаний. В 1996 г. комиссия при Министерстве экономики РФ одобрила выдачу 17 лицензий на право заниматься лизинговой деятельностью. Начиная с 1997 г. лицензии стали выдавать как резидентам, так и нерезидентам [6, с. 94].

В октябре 1994 г. создано некоммерческое объединение «Рослизинг» для координирования работы аффилированных организаций, а также представительства и защиты корпоративных прав и интересов. До середины 1998 г. лизинговая деятельность постепенно набирала обороты, кризис 1998 г. снизил темпы, которые затем восстановились. Положительным фактором развития лизинга стала отмена лицензирования лизинговой деятельности, принятие целого ряда нормативно-правовых актов.

Отметим, что в российской практике используют два понятия: «аренда» и «лизинг», а нормативно-правовое регулирование включает два источника - Гражданский кодекс РФ и Федеральный закон [1;2].

В Гражданском кодексе РФ (далее ГК РФ) в главе 34 (ст. 606) дается определение договора аренды, который подразумевает обязательство арендодателя (наймодателя) о передаче имущества арендатору (нанимателю) «за плату во временное владение и пользование или во временное пользование» [1, ст. 606]. По договору 
аренды объектом выступают земельные участки, обособленные природные объекты, предприятия и другие имущественные комплексы, здания, сооружения, оборудование, транспортные средства. В той же главе ГК РФ определяется «договор финансовой аренды» или лизинг. В нем предусмотрена обязанность арендодателя приобретения в собственность указанного арендатором имущества и предоставления арендатору этого имущества «за плату во временное владение и пользование». Предметом лизинга являются любые непотребляемые вещи, кроме земельных участков и других природных объектов (в том числе предприятия и другие имущественные комплексы, здания, сооружения, оборудование, транспортные средства и другое движимое и недвижимое имущество) [2]. В таблице 1 представлены основные различия между арендой и лизингом.

Таблица 1

\section{Сравнение понятий аренда и лизинг}

\begin{tabular}{|l|l|l|}
\hline Сравнительный признак & \multicolumn{1}{|c|}{ Аренда } & \multicolumn{1}{|}{ Лизинг } \\
\hline Вид рыночных отношений & Отсутствие продажи актива & $\begin{array}{l}\text { Наряду с лизингодателем и лизингополучателем } \\
\text { сделке принимает участие продавец актива }\end{array}$ \\
\hline Договор & Договор аренды & Договор лизинга, договор купли-продажи \\
\hline Доставка актива & Производитель, агент или владелец & Лизинговая компания \\
\hline Риски & Риски лежат на арендодателе & $\begin{array}{l}\text { Риски может нести как лизингодатель, так и ли- } \\
\text { зингополучатель }\end{array}$ \\
\hline
\end{tabular}

Составлено авторами по материалам исследования

В Федеральном законе «О финансовой аренде (лизинге)» определено также, что вид инвестиционной деятельности по приобретению имущества и передаче его в лизинг называется лизинговой деятельностью [2].

При этом лизинговая деятельность может быть внутренней (лизингодатель и лизингополучатель являются резидентами России) и международной (лизингодатель или лизингополучатель является нерезидентом РФ) [2]. Отличительные признаки договора лизинга представлены на рисунке 1.

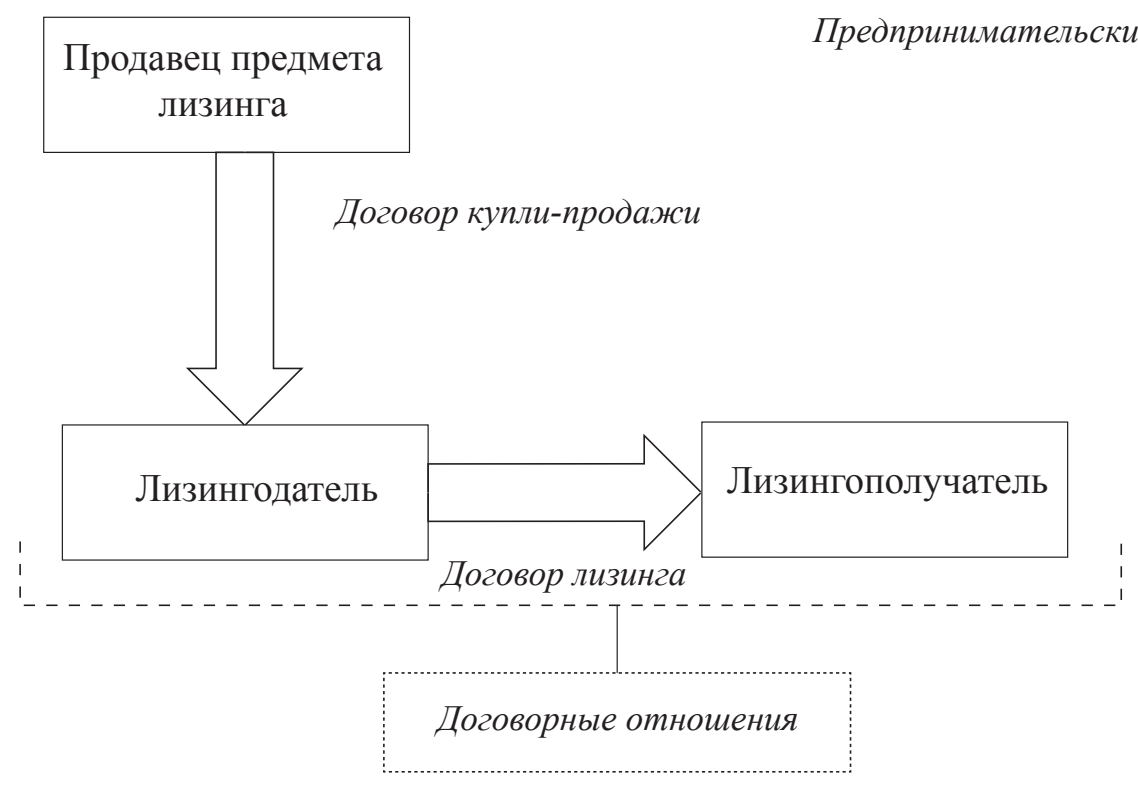

Составлено авторами по материалам исследования

Рис. 1. Отличительные признаки лизингового договора 
Исходя из рисунка 1 сформулируем отличительные признаки лизингового договора:

- договорная основа. Лизинг предполагает заключение двух или более договоров. Заключается договор купли-продажи, во-вторых - договор лизинга. Зачастую лизинговая сделка может сопровождаться и иными договорами;

- участие трех сторон в лице лизингодателя, лизингополучателя и продавца предмета лизинга;

- наличие предпринимательских целей. Гражданским кодексом предусмотрено, что деятельность, осуществляемая самостоятельно, на свой риск, направленная на систематическое получение прибыли от пользования имуществом (предметом лизинга) является предпринимательской;

- приобретение имущества специально для передачи в лизинг. Финансовая аренда (лизинг) включает специальную закупку предмета лизинга и относится к инвестиционной деятельности.

Безусловно, роль лизинговых компаний в мировой экономике значительна. Так, отчет компании White Clarke Group показывает уверенную перспективу отрасли, она демонстрирует значительный рост и представляет новые и инновационные способы финансирования оборудования для компаний по всему миру [14].

В пятерку мировых лидеров входят: США, Англия, Китай, Германия, Япония. В пятерке крупнейших лизинговых рынков США остаются на первом месте, однако согласно обзору деятельности по финансированию оборудования в США наблюдалось замедление роста с 11,10\% в 2015 г. до 2,54\% в 2016 г.

Китай продолжает стремительный рост в сфере лизинга, занимая по величине второе место (после США) лизингового рынка, в 2016 г. объем составил 206 млрд долл. США. Рост рынка значителен, в экономике Китая лизинг рассматривается как важный финансовый инструмент.

Великобритания и Германия позиционируются как третий и четвертый по величине лизинговые рынки в мире и остаются доминирующими игроками в Европе, на долю которых приходится $42 \%$ всего европейского рынка. В 2016 г. Великобритания показала значительный темп роста на 8,98\% по сравнению с предыдущим годом, даже на фоне сложных экономических условий в связи с неопределенностью переговоров по выходу страны из Европейского союза. Германия зафиксировала положительный рост на 3,42 \% по сравнению с 2015 г., с объемом рынка в 64,3 млрд долл. США.

В Японии наблюдалось небольшое снижение объема сделок в 2016 г. на 1,3\%. Однако рынок по-прежнему остается вторым по величине рынком в Азии после Китая.

Исходя из таблицы 2 отметим, что Россия находится в первой десятке стран по объему рынка лизинга. Кроме того, Россия демонстрировала высокий рост объема рынка лизинга, по сравнению с предыдущими годами стагнации. Так в 2016 г. темпы роста составили около $34 \%$ (для сравнения в Германии этот показатель составляет $3 \%$ ). Значительный рост произошел на рынке лизинга машин (31\%), оборудования (39\%) [8]. Лизинг недвижимого имущества продемонстрировал негативную динамику.

Таблииа 2

Объем рынка лизинга в разбивке по странам

\begin{tabular}{|c|c|c|c|}
\hline \multirow{2}{*}{$\begin{array}{c}\text { Место } \\
\text { в мире }\end{array}$} & \multirow{2}{*}{ Страна } & \multicolumn{2}{|c|}{ Объем рынка, млрд долл. США } \\
\cline { 2 - 4 } & & $\mathbf{2 0 1 1}$ г. & $\mathbf{2 0 1 6}$ г. \\
\hline 2 & США & 193,90 & 383,87 \\
3 & Китай & 63,72 & 206,7 \\
4 & Великобритания & 13,38 & 81,77 \\
5 & Германия & 52,49 & 64,30 \\
6 & Япония & 50,75 & 59,42 \\
6 & Франция & 30,89 & 47,80 \\
7 & Италия & 25,46 & 22,80 \\
\hline
\end{tabular}

Источник: [13; 14] 
Рассмотрим особенности лизинга в РФ.

Во-первых, следует отметить разницу в размерах лизингового рынка. Несмотря на то, что Россия занимает седьмое место по лизинговым операциям на мировой арене, она по-прежнему значительно отстает от европейских стран таких как, как Германия, Великобритания и Франция (Таблица 2).

Во-вторых, в России значительно преобладает сфера big ticket (ж/д техника, авиационная техника, суда). Другим отличием является предусмотренный размер лизинговых платежей. В Евросоюзе различия могут составлять несколько десятых процента, тогда как в РФ несколько процентов. Это связано с тем, что западный рынок более стабилен, и конкуренция с фирмами там сильнее, поэтому условия контракта прозрачны. В контрактах российских фирм нельзя исключать множество скрытых платежей [3, с. 58].

Лизинговые компании в России предъявляют более либеральные и гибкие требования к заемщикам. Хотя расчет рисков лизинговых компаний сложнее в российских условиях, а количество арендодателей, отвечающих «идеальным» параметрам намного меньше, чем на Западе, российские лизинговые компании более лояльны к клиентам.

Российский лизинговое законодательство допускает существенную свободу договорных отношений между сторонами лизинговой сделки, что позволяет действовать с учетом интересов обеих сторон.

В 2017 г. объем лизингового бизнеса в России вырос на $48 \%$ и достиг 1,1 трлн рублей [9]. На рисунке 2 представлена динамика объема лизингового рынка в России.

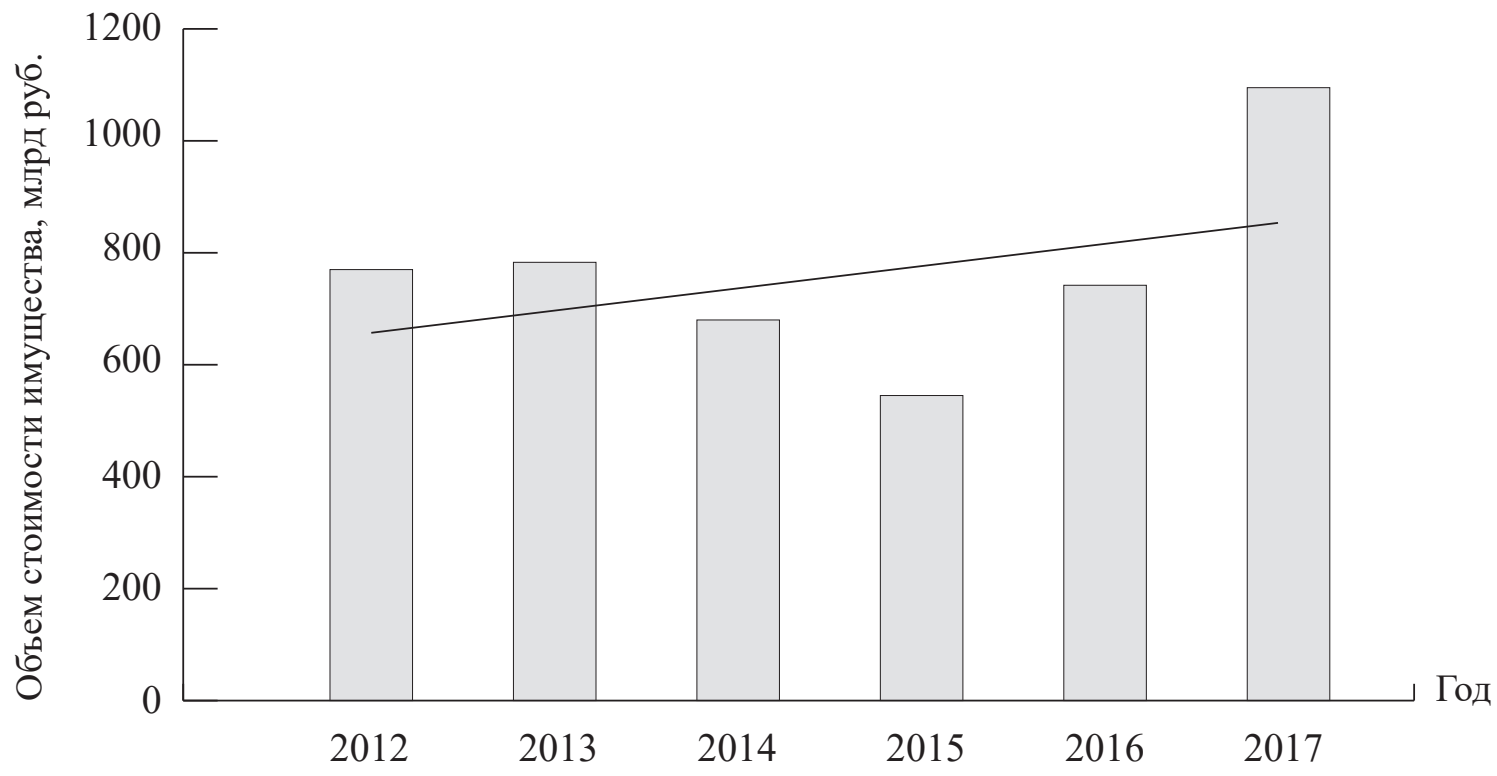

Источник: [9]

Рис. 2. Объем лизингового бизнеса в 2012-2017 гг., млрд руб.

Основной рост произошел в сегменте железнодорожного транспорта, который продемонстрировал рост впервые с 2011 года, а также за счет лизинга автомобилей. Кроме того, значительная государственная поддержка продаж грузовых автомобилей привели к увеличению числа лизинговых сделок.

Подчеркнем, что на рынке лизинга в России на транспортные сегменты на 1 января 2018 г. приходится около $80 \%$ лизингового портфеля (рис. 3) [9].

На рынке лизинга в России выделяют следующих участников: государственные лизинговые компании (6,5\% рынка), лизинговые компании, принадлежащие банковским группам $(51,4 \%)$, лизинговые компании, входящие в промышленные группы (8,9\%), независимые лизинговые компании (33,2\%) [7].

Таким образом, на лизинговые компании, принадлежащие банковским группам, приходится большая часть рынка.

Ежегодно рейтинговое агентство «Эксперт РА» составляет рэнкинг лизинговых компаний России (см. табл. 3) [10]. 


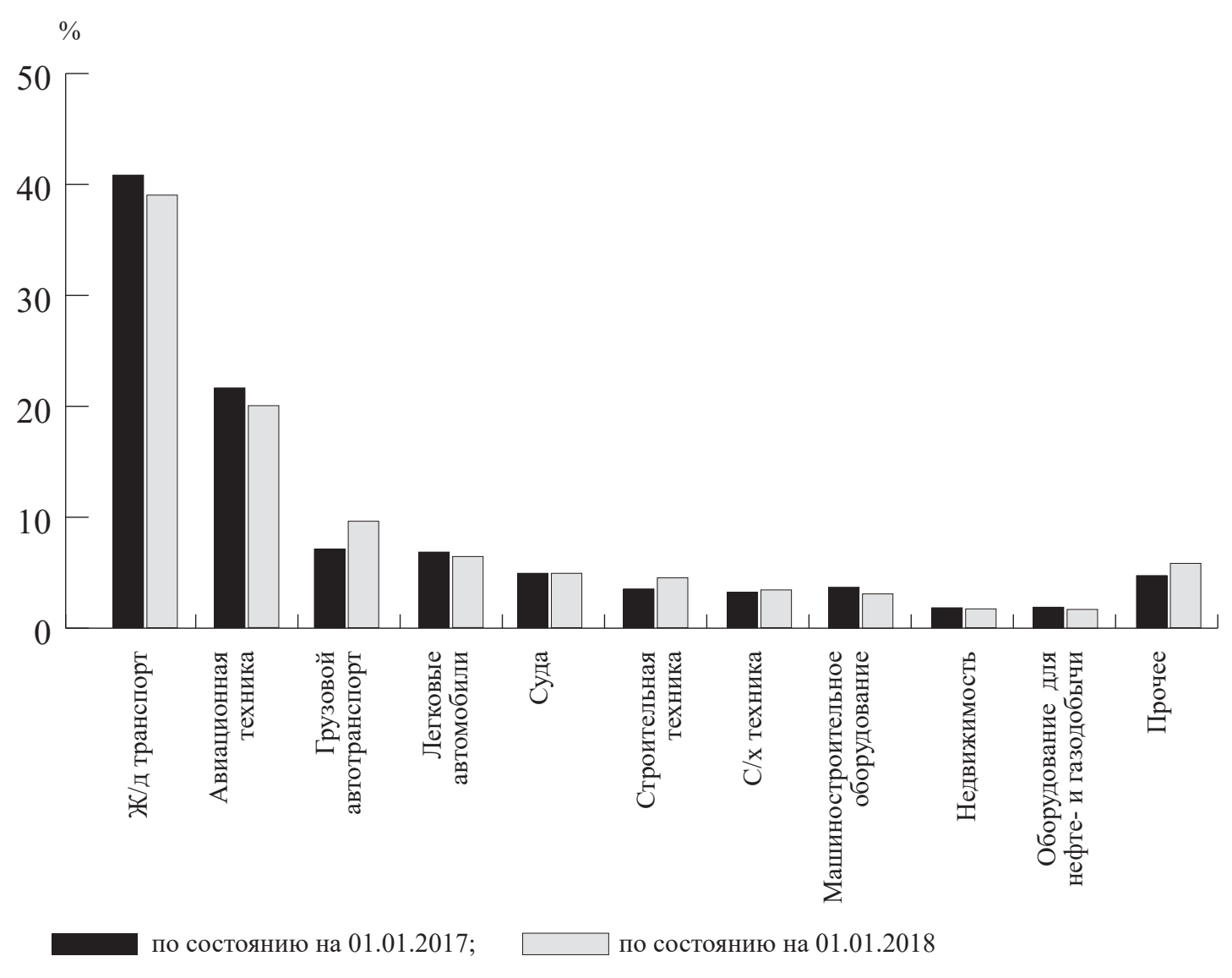

Источник: [9]

Рис. 3. Сегменты лизинга в России, в процентах

Таблииа 3

Топ-5 лизинговых компаний в 2017 г. и в 2018 г.

\begin{tabular}{|c|c|c|c|c|c|c|}
\hline \multicolumn{2}{|c|}{$\begin{array}{c}\text { Место по новому } \\
\text { бизнесу }\end{array}$} & \multirow{2}{*}{ Наименование компании } & \multirow{2}{*}{$\begin{array}{c}\text { Объем нового } \\
\text { бизнеса, } 2017 \text { г., } \\
\text { млн руб. }\end{array}$} & \multirow{2}{*}{$\begin{array}{c}\text { Сумма новых } \\
\text { договоров } \\
\text { за } 2017 \text { г., } \\
\text { млн руб. }\end{array}$} & \multicolumn{2}{|c|}{$\begin{array}{c}\text { Текущий портфель, } \\
\text { млн руб. }\end{array}$} \\
\hline 01.01 .2018 & 01.01.2017 & & & & $\begin{array}{c}01.01 . \\
2018\end{array}$ & $\begin{array}{c}01.01 . \\
2017\end{array}$ \\
\hline 1 & 1 & ПАО «ГТЛК» & 142021 & 242527 & 534349 & 337601 \\
\hline 2 & 2 & «СБЕРБАНК ЛИЗИНГ» (ГК) & 125709 & 171476 & 402328 & 375081 \\
\hline 3 & 5 & «ВЭБ-лизинг» & 108925 & 140147 & 351787 & 524660 \\
\hline 4 & 3 & «ВТБ Лизинг» & 100209 & 155832 & 406781 & 380416 \\
\hline 5 & 4 & «ЛК «Европлан» & 61438 & - & 60905 & 40220 \\
\hline
\end{tabular}

Источник: [10]

Подчеркнем, что рэнкинг довольно стабильный, основными игроками являются: ПАО «Государственная транспортная лизинговая компания» (далее - ПАО «ГТЛК»), АО «Сбербанк лизинг» с долей на рынке (по объему нового бизнеса) около $26 \%$. Роль лизинга очень важна при решении вопроса о модернизации экономики, но до сих пор она оценена не в полной мере. Так, например, недооценена его роль в железнодорожной или авиационной отрасли, сельском хозяйстве, так как все это невозможно без масштабной реформы отрасли. Рассмотрим это на примере одной из самых больших сделок на грузоперевозочном рынке. ПАО «ГТЛК» приобретает у НПК «Объединенная Вагонная Компания», которая принадлежит бизнесмену А. Несису, сразу 4,5 тысячи новых железнодорожных полувагонов. При этом уже известен 
и конечный их получатель. Вся партия отдается в лизинг компании «Восток1520», подконтрольной С. Генералову. Срок лизинга составляет 15 лет, а сумма сделки - 31,3 млрд рублей [11].

Отметим, что эксперты прогнозируют дальнейший рост лизинга в РФ. По их мнению, существует два сценария развития. Предполагается, что объем лизингового рынка в 2018 г. вырастет на $20 \%$ и составит около 1,3 трлн рублей. Согласно негативному прогнозу, рост составит около $10 \%$, а объем рынка лизинговых сделок в 2018 г. достигнет 1,2 трлн рублей.

В первом случае, рост произойдет из-за рекордных темпов прироста автомобильного сегмента и железнодорожного сегмента (благодаря государственному субсидированию), а также благодаря дальнейшему увеличению замены парка подвижного состава. Кроме того, за счет сделок в авиапромышленности, объем аренды отечественных самолетов вырастет на $15 \%$. Прочие сегменты также продемонстрируют рост в $15 \%$, вследствие дальнейшего уменьшения фондирования лизинговых сделок.

Во втором случае, рост автомобильного сегмента, а также авиационного лизинга составит не более $15 \%$. Объем нового бизнеса с железнодорожным транспортом увеличится не более чем на $10 \%$ вследствие минимизации профицита полувагонов в связи с разрывом договорных отношений крупных игроков, а прочие сегменты вырастут на $5 \%$. Безусловно, объемы лизингового рынка по-прежнему будут находиться в прямой зависимости от темпов роста экономики России и реализации государственных программ с применением лизинга.

\section{Библиографический список}

1. Гражданский кодекс Российской Федерации (часть вторая) от 26.01.1996 г. № 14-Ф3 (ред. от 29.07.2018 г.) [Электронный ресурс]. - Режим доступа: Справочная правовая система «КонсультантПлюс» http://www.consultant.ru/cons/ (дата обращения: 20.12.2018).

2. Федеральный закон «О финансовой аренде (лизинге)» от 29.10.1998 г. № 164-Ф3 (ред. от 16.10.2017 г.) [Электронный pecypc]. - Режим доступа: Справочная правовая система «КонсультантПлюс» http://www.consultant.ru/cons/ (дата обращения: 20.12.2018).

3. Дун, И. Р. Анализ рынка лизинга инновационных продуктов в России // Лизинг. - 2015. - № 8. - С. 58-60.

4. Курилец, И. В. Ретроспективный обзор становления лизинговых отношений и развития специального законодательства для лизинга в России // Лизинг-Ревю. - 2014. - № 2. - С. 32-37.

5. Лещенко, М. И. Основы лизинга. Учебное пособие. - Москва: Финансы и статистика, 2014. - 334 с.

6. Ястребов, К. Л. [и др.]. Историческая объектная структура российских лизинговых предприятий / К. Л. Ястребов, В. Ю. Конюхов, Г. Е. Дыкусов, Т. И. Карлина, Р. Н. Горбунов // Транспортная инфраструктура Сибирского региона. 2015. - T. 2. - C. 92-97.

7. Берегатнова, Е. В. Рынок лизинга РФ: состояние, перспективы [Электронный ресурс] // Национальный исследовательский университет ВШЭ, 2016. - 47 с. - Режим доступа: https://dcenter.hse.ru/data/2017/01/13/1115379811/Рынок\%20лизинга\%20 РФ\%202016.pdf (дата обращения: 20.12.2018).

8. Европейский рынок лизинга в 2016 году [Электронный ресурс]. - Режим доступа: http://www.leaseurope.org/uploads/ documents/LeaseuropeFF_16.pdf (дата обращения: 20.12.2018).

9. Рынок лизинга: итоги 2017 года и перспективы развития [Электронный ресурс] // Рейтинговое агентство «Эксперт РА».Режим доступа: https://raex-a.ru/project/leasing/2018/resume (дата обращения: 20.12.2018).

10. Рэнкинг лизинговых компаний России по итогам 2017 года [Электронный ресурс] - Режим доступа: https://raexpert.ru/ rankingtable/leasing/leasing_2017/main/ (дата обращения: 20.12.2018).

11. Государственная транспортная лизинговая компания [Электронный pecypc]. - Режим доступа: https://www.gtlk.ru (дата обращения: 20.12.2018).

12. Equipment Leasing \& Finance Foundation [Электронный ресурс]. - Режим доступа: https://www.leasefoundation.org (дата обращения: 20.12.2018).

13. Global Leasing Report 2018 [Электронный ресурс] // White Clarke Group - Leading Finance Technology. - Режим доступа: https://www.whiteclarkegroup.com/reports/global-leasing-report-2018 (дата обращения: 20.12.2018).

14. Ezzell, J. R., Vora P. P. Leasing versus purchasing: direct evidence on a corporations motivations for leasing and consequences of leasing, The Quarterly Review of Economics and Finance. - 2001. - V. 41. - № 1. - P. 33-47.

15. IAS 17 Leases [Электронный ресурс] // The International Financial Reporting Standards Foundation. - Режим доступа: https://www.ifrs.org/issued-standards/list-of-standards/ias-17-leases/ (дата обращения: 20.12.2018). 


\section{References}

1. Grazhdanskii kodeks Rossiiskoi Federatsii (chast’ vtoraya) ot 26.01.1996 g. № 14-FZ (red. ot 29.07.2018 g.) [Civil Code of the Russian Federation (Part Two) dated on January 26, 1996 № 14-FZ (as amended on July 29, 2017)]. Available at: Spravochnaya pravovaya sistema «Konsul'tantPlyus» http://www.consultant.ru/cons/ (accessed 20.12. 2018).

2. Federal'nyi zakon «O finansovoi arende (lizinge)» ot 29.10.1998 g. № 164-FZ (red. ot 16.10.2017) [Federal Law «On financial lease (leasing)» dated on October 29, 1998 № 164-FZ (as amended on 10.16.2017)] Available at: Spravochnaya pravovaya sistema «Konsul’tantPlyus» http://www.consultant.ru/cons/ (accessed 20.12. 2018).

3. Dun I. R. Analiz rynka lizinga innovatsionnykh produktov v Rossii [Analysis of the leasing market for innovative products in Russia], Lizing, 2015, I. 8, pp. 58-60.

4. Kurilets I. V. Retrospektivnyi obzor stanovleniya lizingovykh otnoshenii i razvitiya spetsial'nogo zakonodatel'stva dlya lizinga $\mathrm{v}$ Rossii [A retrospective review of the formation of leasing relations and the development of special legislation for leasing in Russia], Lizing-Revyu, 2014, I. 2, pp. 32-37.

5. Leshchenko M. I. Osnovy lizinga. Uchebnoe posobie [Basics of leasing. Tutorial], Moscow: Finansy i statistika, 2014, 334 p.

6. Yastrebov K. L., Konyukhov V. Yu., Dykusov G. E., Karlina T. I., Gorbunov T.I. Istoricheskaya ob"ektnaya struktura rossiiskikh lizingovykh predpriyatii [Historical object structure of Russian leasing enterprises], Transportnaya infrastruktura Sibirskogo regiona, 2015, V. 2, pp. 92-97.

7. Beregatnova E. V. Rynok lizinga RF: sostoyanie, perspektivy [Russian leasing market: state, prospects], Natsional'nyi issledovatel'skii universitet. Available at: https:/dcenter.hse.ru/data/2017/01/13/1115379811/Рынок\%20лизинга\%20РФ\%202016. pdf. (accessed 20.12.2018).

8. Evropejskii rynok lizinga v 2016 godu [European leasing market in 2016]. Available at: http://www.leaseurope.org/uploads/ documents/LeaseuropeFF_16.pdf (accessed 20.12.2018).

9. Rynok lizinga: itogi 2017 goda i perspektivy razvitiya [Leasing market: results of 2017 and development prospects], Reitingovoe agentstvo «Ekspert RA» [Rating agency «Expert RA»]. Available at: https://raex-a.ru/project/leasing/2018/resume (accessed 20.12.2018).

10. Renking lizingovykh kompanii Rossii po itogam 2017 goda [Ranking of leasing companies in Russia at the end of 2017]. Available at: https://raexpert.ru/rankingtable/leasing/leasing_2017/main/ (accessed 20.12.2018).

11. Gosudarstvennaya transportnaya lisingovaya kompaniya [State Transport Leasing Company]. Available at: https://www.gtlk. ru (accessed 20.12.2018).

12. Equipment leasing \& Finance foundation. Available at: https://www.leasefoundation.org (accessed 20.12.2018).

13. Global leasing report 2018, White clarke group - leading finance technology. Available at: https://www.whiteclarkegroup.com/ reports/global-leasing-report-2018 (accessed 20.12.2018).

14. Ezzell, J. R., Vora P. P. Leasing versus purchasing: direct evidence on a corporations motivations for leasing and consequences of leasing, The quarterly review of economics and finance, 2001, V. 41, № 1, pp. 33-47.

15. IAS 17 Leases, The international financial reporting standards foundation. Available at: https://www.ifrs.org/issued-standards/ list-of-standards/ias-17-leases/ (accessed 20.12.2018). 